\title{
Online Reality Show Negatively Impacts on Audience Perceptions of Sexism
}

\author{
$\mathrm{Yu} \mathrm{Bao}{ }^{1,2 *}$ \\ ${ }^{1}$ International College Beijing, China Agricultural University, Beijing, 100083, China \\ ${ }^{2}$ College of Liberal Art and Science, University of Colorado, Denver, Colorado 80014, The United States of America \\ *Corresponding author. Email: yu.bao@ucdenver.edu
}

\begin{abstract}
Due to the development of Internet, Chinese corporations have exploited multiple Internet-based application. Online media platform is one of them. In order to become competitive among online video applications, Internet enterprises create copyrighted content and build up media spectacle in the production. Iqiyi produced Rap of China in 2017 in the form of rap performance contest. However, Iqiyi reproduces patriarchal structure and message about sexism into Rap of China. The gendered discriminating information has negative impact on audiences. Considering this pedagogical significance of online reality show, this study suggests for a comprehensive perception system about metaliteracy which refers to an internal self-protection. In order to apply meta technology to practice, metadata, as a statistical reference and theoretical basis, is accurate and convenient for the public to use when surfing the Internet.
\end{abstract}

Keywords: Online Media, Media Convergence, Media Spectacle, Metadata, Metaliteracy

\section{INTRODUCTION}

Thanks to the development of the Internet, today there are more diverse online video resources available on the online media platform. Iqiyi is one of those Internet-based media platforms. In 2017, Iqiyi produced and copyrighted a reality show called Rap of China. As Iqiyi popularizes Rap songs and Hip-Hop cultures to mass audiences however, Iqiyi reproduces gendered power divergence between producers to rappers and between male rappers to female rappers. Therefore, this paper conducts an investigation by using both qualitative and quantitative methods. The study specifically focuses on one contest section in Rap of China, namely the trial which provides 60 seconds for rappers to perform rap songs. This research hopes to find the answer to the question "How does Iqiyi as a well-known online media platform rationalize the gendered power inequalities and reproduce a structural sexism of male domination in Rap of China?"

Up to 2020, Iqiyi has produced Rap of China for three seasons. This research will exclusively focus on Rap of China Season One and Rap of China Season Two and make comparison between the two seasons in terms of medium, production, and content. I posit my viewpoint in two dimensions. The first is that in both season of Rap of China, Iqiyi reproduces gendered inequality and structural sexism by taking the advantage of the characteristic of online media and inviting gendered imbalanced lineup of producers and rappers. The second is that in Rap of China Season Two, Iqiyi neglects the diversification of rappers' identity and portrays the profession of female with inferiority.

This study will take "media spectacle" as the theoretical foundation. As Kellner [1] explains, media spectacles which demonstrates who has power and who is powerless, highlighting a key research perspective I take in this study. Rap of China presents a spectacle of power hierarchy in which producers have the greatest power to select rappers, and male rappers are in an advantaged position when compared with female rappers.

\subsection{Contribution}

This paper reveals the stereotypical phenomenon from online reality show by observing Iqiyi's production - Rap of China with the perspective of "media spectacle". Moreover, this case study builds up theoretical fundaments about metaliteracy as self-protection mechanism with which audiences are able to prevent to be internally colonized

\subsection{Paper Structure}

The rest of the paper is organized as follows. Section 2 reports the result of quantitative and qualitative coding in regards with media spectacle, which include "media convergence" from Henry Jenkins, "internal colonization" and "active audience" from Stuart Hall, postmodernism from Storey. In section 3, the research ends up with the idea of "metaliteracy" as a solution in regards to the consumption of implicitly stereotypical information from online reality show. Also, in which, McPherson's "metadata" will be the fundamental theory of "meta literacy" specifically for online media platform and online reality show. 


\section{ANALYSIS}

\subsection{Iqiyi as Internet-based product of media convergence}

Iqiyi is the production of media convergence. As Henry Jenkins defines, "Media convergence is more than simply a technological shift. Convergence alters the relationship between existing technologies, industries, markets, genres, and audiences"[2]. Internet cooperations like Iqiyi, Youku, and Tencent develops their own online media platform and administrate published content with complete authority. What makes Iqiyi becomes one of the monopolizing online media platform is not due to technology behind the online platform, but due to the function, content disseminating on Iqiyi's platform. Figure 1 [3] and Figure 2 [4] reveals different advantages of Iqiyi, Tencent, and Youku respectively.

Figure 1 refers to the table showing the quantity of Iqiyi, Tencent, and Youku's copyright-owned resources and cost for becoming VIP. By paying for VIP, consumers will have a full access to all Iqiyi copyright-owned contents. Comparing figure 1 and figure 2 together, Iqiyi stands in an advantageous position. The quantity of copyright of Iqiyi is at the second place comparing with Tencent and Youku and the cost for VIP monthly is at the second place as well. That is to say, the cost of becoming Iqiyi's VIP is equivalent with what Iqiyi provides for VIP consumers.

The figure 2 illustrates 6 evaluating dimensions. Which platform has done a better job within the dimension will receive a " $\sqrt{ }$ " figure. As figure 1 shows, Iqiyi has done a better job on platformization. Iqiyi synthesizes their advantageous position of owning copyright contents with VIP service. This management measure makes VIP consumers feel that their spend is worthy for what they have received. Both Tencent and Youku lack of a comprehensive development for VIP services. Above all, this research dives into specific dimension to compare functions which Iqiyi, Tencent and Youku exploit for establishing platformization. And Iqiyi wins. Rap of China is such a copyright-owned production from Iqiyi which embed patriarchal structure into the Season One. However, Iqiyi realizes the problem and makes adjustment to controversial patterns and lineup.

\subsection{Lineup of producers in Rap of China Season One and Season Two}

At the first season of Rap of China, in trial of 60 seconds rap, Iqiyi invites 3 groups of producers to evaluate rappers' performance. Fiske lists seven "subjectivity positions" including self, gender, age-group, family, class, nation, ethnicity [5]. The 7 subjectivity positions are also the most basic and familiar identities while talking about identification for someone. Based on seven "subjectivity positions", I will choose 4 from the 7 categories. Due to the unique context of the rap competition, the study substitutes "Class" by "Profession". In Rap of China Season One, Iqiyi invites four celebrities to constitute the lineup of producers. Iqiyi divides the lineup into three groups: respectively they are Kris Wu, Weibo Pan, Zhenyue Zhang \& Mc Hotdog. Figure 3 demonstrates demographic information following Fiske's subjective positions.

Figure 3 [6] indicates with 4 most frequently appeared identities - Male, Han, middle-aged, and professional entertainers. According to Rap of China's competition system, producers are the most powerful existence in the show; they have the absolute power to determine rapper's performance as professional or not. In this sense, Han, middle-aged males take this advantageous position. Iqiyi ignores the implicit male-inclined rule behind the lineup and construct a patriarchal structure inside Rap of China Season One.

Iqiyi makes adjustment for lineup of producers in Rap of China Season Two. They invite GEM to join with Weibo Pan as a group. Iqiyi continues to set up three groups respectively they are Kris $\mathrm{Wu}$, Weibo Pan \& GEM, and Zhenyue Zhang \& Mc Hotdog. Figure 4 is the updated version of Figure 3 which records for demographic information of the 5 producers based on Fiske's list [5].

Figure 4 [7] updates GEM demographic information. According to the table above, except for profession, age and ethnicity, all the other identities are different from the other 4 producers. GEM is a female, Han, middle-aged, singer who is born in Shanghai - mainland China. The purpose of Iqiyi inviting GEM as part of the lineup is to counterbalance the male-dominant structure in Rap of China Season One.

Rap of China conveys the message about power divergence to audiences while audiences are overwhelming in the contest. Identities do not show up in sequence but instead identities are intersecting with each other according to Kimberlé Crenshaw [8]. Male, Han ethnicity, middle-aged, and singer all together refer to the most frequently appeared identity message based on figure 3 and figure 4 . Identities with higher frequency develops as dominant majority inside Rap of China. On the other hand, female, non-Han ethnicity, non-middle-aged refer to the inferior identities that intersect together invisibly and be in disadvantageous position in the contest. 


\begin{tabular}{l|c|c|c}
\hline & Iqiyi & Tencent & Youku \\
\hline Reality Show & 20 & 40 & 9 \\
\hline TV Series & 64 & 76 & 60 \\
\hline Films & 45 & 43 & 44 \\
\hline Cost for VIP monthly & $¥ 19.8$ & $¥ 20$ & $¥ 15$ \\
\hline
\end{tabular}

Figure 1. Quantity of Iqiyi, Youku, and Tencent Copyright-owned Resources \& Cost for VIP [3]

\begin{tabular}{l|c|c|c}
\hline & Iqiyi & Tencent & Youku \\
\hline Coverage of Customers from All Age Level & & & $\sqrt{ }$ \\
\hline Videos with Customizing Recommendation Function & & & $\sqrt{ }$ \\
\hline Exclusive Content for VIP & $\sqrt{ }$ & & \\
\hline Function Specific for Fans Network & $\sqrt{ }$ & & \\
\hline Copyright Contents & & $\sqrt{ }$ & \\
\hline Hot Spot of Copyright Contents & & & \\
\hline
\end{tabular}

Figure 2. Comparison between Iqiyi, Tencent, and Youku in Regards to Developed Function [4]

\begin{tabular}{|c|c|c|c|c|}
\hline Gender & Male & Male & Male & Male \\
\hline Age & 29 & 39 & 45 & 41 \\
\hline Profession & Actor \& Singer & Singer, Actor \& Presenter & Rapper \& Singer & Rapper \& Singer \\
\hline Nationality & Canadian & American & Taiwanese - China & Taiwanese - China \\
\hline Ethnicity & Han & Han & Amis & Han \\
\hline
\end{tabular}

Figure 3. Demographic Information of Producers in Rap of China in Season One [6]

\begin{tabular}{|c|c|c|c|c|c|}
\hline & Kris Wu & Weibo Pan & GEM & Zhenyue Zhang & Mc Hotdog \\
\hline Gender & Male & Male & Female & Male & Male \\
\hline Age & 29 & 39 & 29 & 45 & 41 \\
\hline Profession & $\begin{array}{l}\text { Actor \& } \\
\text { Singer }\end{array}$ & $\begin{array}{c}\text { Singer, Actor \& } \\
\text { Presenter }\end{array}$ & Singer & Rapper \& Singer & Rapper \& Singer \\
\hline Nationality & Canadian & American & Chinese & Taiwanese - & Taiwanese - \\
\hline Ethnicity & Han & Han & Han & Amis & Han \\
\hline
\end{tabular}

Figure 4. Demographic Information of Producers in Rap of China in Season Two [7]

\subsection{Identification for Rappers}

According to media agenda setting theory, "it posits a relationship between the relative emphasis given by the media to various topics and the degree of salience these topics have for the general public" [9]. Iqiyi provides two strategies for creating topics for audiences to discuss about in Rap of China Season One and Rap of China Season Two. In Rap of China Season One, Iqiyi portrays rappers and rap performance as might and vulgar culture. Rap of China Season One displays the conflict between male rapper and female rappers. Male rappers will show their dissatisfaction to the result of 60 seconds trial by changing their facial expression and using sensitive words to comment on female 
rappers' performance. Iqiyi displays those conflicts with the purpose to achieve a higher page view for Rap of China. Differently, in Rap of China Season two, Iqiyi changes strategy by adding identity for rappers.

Iqiyi produces a media spectacle in Rap of China Season Two by collapsing the difference between high culture and low culture regarding with post-modernism. According to Storey [10], "the distinction between 'high' and 'low' culture seems less and less meaningful. In this sense, it is a sensibility in revolt against what is seen as the cultural elitism of modernism." From Figure 5 [11], it shows that in Rap of China, Iqiyi provides the diversity of rappers identity. Lawyer, student at the top ranking university, idol, professional rappers and stay-at-home mom all have received pass from 3 groups of producers. Overall, the strategy of adding identity for rappers provides the idea of post-modernism into Rap of China Season Two.

However, a male-dominant situation embeds in the identification of Iqiyi. Iqiyi collapses high and low culture difference but create a class difference between male rappers and female rappers. From Figure 7, Iqiyi identifies Dai Baojing and Chen Zitong as "stay-at-home mom" and "runner-up of another reality show competition".
Comparing with the profession of lawyer, and student of Tsinghua University and UCLA, the society defines the profession of female rappers with an inferior position. After Dai Baojing's performance, Weibo Pan asks about the purpose of taking part in Rap of China: "Do you think you have abandoned your husband and child? "[12] Weibo Pan uses patriarchal ideologies to question Dai Baojing's decision. As Stuart Hall implies about "active audiences" [13], "Dominant" readings are those in which audiences appropriate texts in line with the interests of the dominant culture and the ideological intentions of a text, as when audiences feel pleasure in the restoration of male power, law and order, and social stability." On the basis, the question refers to a topic that Iqiyi creates for audience to discuss about according to agenda setting theory; however, on the background the question queries female rapper about the conflict between hobby and family. Overall, The question provides audience with pleasure in this restoration of male power from Weibo Pan. Iqiyi eliminates the difference between high culture and low culture at the expense of question female about her choice on "career" and "family".

\begin{tabular}{c|c|c|c}
\hline Name & Gender & Pass/Fail & Identity \\
\hline Duo Lei & Male & Pass & Student of Tsinghua University \\
\hline Yang HeSu & Male & Pass & Student of University of California Los Angles \\
\hline Na Wukeru & Male & Pass & Music Producer \\
\hline Dai Baojing & Female & Pass & Run-at-home Mom \\
\hline Chen Zitong & Female & Pass & Idol \\
\hline Xu Shengen & Male & Pass & Lawyer \\
\hline J. D. & Male & Pass & Fail in Season One \\
\hline Al Rocco & Male & Pass & Fail in Season One \\
\hline Xiao Qinglong & Male & Pass & \\
\hline
\end{tabular}

Figure 5. Identity that Iqiyi provides for Rapper [11]

\section{CONCLUSION AND SOLUTION}

Based on the content comparison between the two season of Rap of China, Iqiyi takes action to deal with the patriarchal structure in Rap of China Season One. But in the second season, by adding identification as "media spectacle", Iqiyi reinforces the stereotypical understanding on female rappers. Also, the join of female producers does not change the main-dominant power distribution on the ground. That is to say, Iqiyi produces Rap of China as a commodity to help Iqiyi increase income and popularity under the competition between Youku and Tencent. The creation of topic is the tradeoff of portraying rap culture with high compatibility between high culture and low culture.

Because of internal colonization [14], the audience of Rap of China are actively engaging with the content. That is to say, audiences will believe in everything that media reflect on stereotypical structure in real patriarchal society. Iqiyi constructs a male-dominant media spectacle and publics act as "active audience" who are interested in the dominant culture and the ideological intentions of the reality show. The internally automatic engagement with stereotypical content in reality show proves the need of "metaliteracy"[15].

\subsection{Metadata \& Metaliteracy}

The invention of "media literacy", "digital literacy", and "metaliteracy" is not only for distinguishing the "fake news" and misleading information. The good capability of driving the "literacy" is to help us stay with keep the mind clean all the time in this information-booming era. "Literacy" is a self protection mechanism. That is to say, people should develop literacy in our own sense as a kind of ideology. In this sense, "literacy" must shift to a higher level in order to own a "wider field of vision" and become self alerting while surfing through the stream of information. So, "literacy" have to sublime to a higher level; that is namely meta- 
literacy. Mackey and Jacobson have defined for "metaliteracy"

Metaliteracy is an overarching and self-referential framework that integrates emerging technologies and unifies multiple literacy types. This redefinition of information literacy expands the scope of generally understood information competencies and places a particular emphasis on producing and sharing information in participatory digital environments. [16]

Mackey and Jacobson implies for the importance of literacy when participating with digital environments. The operation of metaliteracy develops as a conditioned reflex just like human's muscles which realize automatic internal reflection after receiving outside stimulus.

People are not living in vacuum so it is impossible to avoid cyber-citizens to come across with fake and stereotypical information. According to McPherson [17], Metadata refers to content such as information's sources, times, places of production and transmission. McPherson's "metadata" is a perfect fundament for metaliteracy. For the first reason, "metadata" and "metaliteracy" coexist on the same level which is also higher than the level of empirical experiences. Information on the empirical level is what Mackey and Jacobson defines as "the generally understood information competencies". By expanding this scope of information competencies, media users may enter to the meta level. For the second reason, McPherson indicates that the core value of information is metadata with veracity. That is to say, the veracity of metadata builds up a stable information fundament as the raw material for developing metaliteracy. Metadata as the absolute and unchangeable quality for a piece of information reveals the extent of data on social media to be certain. For the third reason, metadata is easily accessible. While someone posts a piece of information on social media, metadata like time, location, person who posts it accompany with the specific information and together show on the cyber society. Metadata provides a stable environment for developing metaliteracy.

Metaliteracy aims to build up the habits of thinking critically while surfing on the Internet. Metadata provides secure fundamental materials for metaliteracy. However, the problem is online media shows do not provide an easily accessibility to metadata. Also, subscribers are more emotionally engaging with the content of the reality show. Because of this, metaliteracy should develop as a selfprotection mechanism while audiences are watching the reality show.

\section{REFERENCES}

[1] J. Meyrowitz, Medium Theory. In D. Crowley \& D. Mitchell (Eds.), Communication Theory Today. Stanford, CA: Stanford University Press, 1994, pp. 50-77

[2] H. Jenkins, The cultural logic of media convergence. International Journal of Cultural Studies, vol. 7, Sage, 2004, pp. 33-43.
[3] Monkeyzmk, Content Comparison between Youku, Tencent and Iqiyi in 2019, 2019, https:// post.smzdm.com/p/adwlgg5p/.

[4] A. Li, Product Operation: Iqiyi, Tecent, Youku's analysis of competitive products, 2019, https://www.jianshu.com/p/fd9ebeb3263c.

[5] J. Fiske, Reading the Popular, A collection of essays analysing different examples of popular culture, London: Unwin Hyman, 1989.

[6] Iqiyi, Rap of China, 2017.

[7] Iqiyi, Rap of China, 2018.

[8] K. Crenshaw, Intersectionality, UK: Cambridge University Press, 2013.

[9] C. R. Ader, A longitudinal study of agenda setting for the issues of environmental pollution, Journalism and Mass Communication Quarterly, vol. 72, 1995, pp. 300-3 II.

[10] J, Storey, Culture Theory and Popular Culture: An Introduction. New York: Routledge, 2015, http://ebookcentral.proquest.com/lib/cudenver/detail.action $?$ docID $=2046454$

[11] Iqiyi, Rap of China, 2018.

[12] W. B. Pan, Rap of China Season Two, Iqiyi, 2018.

[13] S. Hall, Representation: Cultwral repre- sentdtions and signifying practices, Milton Keynes, IK: Open University Press, 1997.

[14] S. Hall, Encoding/decoding. In S. Hall, D. Hobson, A. Lowe, \& P. Willis (Eds.), Culture, media, language: Working papers in cultural studies, vol. 79, London, Hutchinson, 1972, pp. 128-138.

[15] N. A. Cooke, Posttruth, Truthiness, and Alternative Facts: Information Behavior and Critical Information Consumption for a New Age, Information, Community, Policy, vol. 87, 2017.

[16] T. P. Mackey, T. E. Jacobson. Reframing Information Literacy as a Metaliteracy. College and Research Libraries, vol. 76, 2011, pp. 62-78.

[17] E. McPherson, Advocacy Organizations' Evaluation of Social Media Information for NGO Journalism: The Evidence and Engagement Models. American Behavioral Scientist, vol. 59, 2014, pp.124-148 